\title{
BMJ Open Trends in attention-deficit and hyperactivity disorder (ADHD) medications among children and young adults in Ireland: a repeated cross- sectional study from 2005 to 2015
}

\author{
MaryJo Mac Avin, ${ }^{1}$ Mary Teeling, ${ }^{1}$ Kathleen E Bennett (D) ${ }^{2}$
}

To cite: Mac Avin M, Teeling M, Bennett KE. Trends in attentiondeficit and hyperactivity disorder (ADHD) medications among children and young adults in Ireland: a repeated cross-sectional study from 2005 to 2015. BMJ Open 2020;10:e035716. doi:10.1136/ bmjopen-2019-035716

- Prepublication history and additional material for this paper are available online. To view these files, please visit the journal online (http://dx.doi. org/10.1136/bmjopen-2019035716).

Received 12 November 2019 Revised 26 February 2020 Accepted 23 March 2020

\section{Check for updates}

(c) Author(s) (or their employer(s)) 2020. Re-use permitted under CC BY-NC. No commercial re-use. See rights and permissions. Published by BMJ.

${ }^{1}$ Pharmacology and Therapeutics, TCD, Dublin, Ireland

${ }^{2}$ Population Health Sciences, Royal College of Surgeons in Ireland, Dublin, Ireland

Correspondence to Professor Kathleen E Bennett; kathleenebennett@rcsi.ie

\section{ABSTRACT}

Objective This study examined the prescribing patterns of attention-deficit hyperactivity disorder (ADHD) medications in Ireland between 2005 and 2015 in children, adolescents and young adults, and concomitant use of psychotropic medication.

Design Repeated cross-sectional study.

Setting Community setting using pharmacy claims data in Ireland.

Participants Children and young adults aged 0-24 years. Primary and secondary outcomes Authorised medications used to treat ADHD during the study period, methylphenidate, dexamfetamine, lisdexamfetamine dimesylate and atomoxetine were extracted from a national pharmacy claims database. Dispensing of concomitant psychotropic medications including antipsychotics, anxiolytics, hypnotics/sedatives and antidepressants were examined.

Results The number on any ADHD medication ranged from 1913 in 2005 to 4853 in 2015, and the prevalence rate per 1000 eligible population aged $<25$ years increased significantly over time from $5.61(95 \% \mathrm{Cl}$ 5.36 to 5.86$)$ in 2005 to 8.36 (95\% Cl 8.13 to 8.60$)$ in $2015(p<0.0001)$. Negative binomial regression showed significant changes over time for ADHD prescribing $(p<0.001)$, with significantly higher rates across the different age groups. The rates overall were three to five times higher in males. There was a significant increase in the percentage on concomitant antidepressants from $2 \%$ in 2005 to $6 \%$ in $2015(p<0.001)$.

Conclusions There were significantly higher rates of ADHD prescribing in children/adolescents and a significant increase in the coprescribing of antidepressants. The reasons for the increase are unclear but may reflect increasing awareness and diagnosis of the condition.

\section{INTRODUCTION}

Attention-deficit and hyperactivity disorder (ADHD) is a complex, heterogeneous and multifactorial disorder which is characterised by persistent symptoms of inattention, hyperactivity and impulsivity. ${ }^{12} \mathrm{ADHD}$ is the most common childhood neurodevelopmental
Strengths and limitations of this study

- This study was based on a large national sample of children and young adults with accurate ascertainment of medicines.

- This is the first Irish study looking at the prescribing of attention-deficit hyperactivity disorder (ADHD) medications in young adults.

- This repeated cross-sectional study examined rates of prescribing of ADHD medications for children and young adults aged up to 24 years from 2005 to 2015 in Ireland, using negative binomial regression.

- The limitations are that the participants come from a more socially deprived population.

- There was no clinical information including indications for the prescribing of ADHD medications available.

disorder, and it is now recognised that the symptoms and impairments associated with ADHD may persist into adulthood. ${ }^{34}$ There is a huge variation in the prevalence of ADHD in studies conducted in children and adults ${ }^{5-9}$; this variation is thought to reflect methodological issues. ${ }^{8} 10$ A meta-analysis of studies which estimated the prevalence of ADHD as defined by the Diagnostic and Statistical Manual of Mental Disorders, fourth edition (DSM-IV) reported a prevalence of ADHD in 5.9\%-7.1\% in children and $5 \%$ in adults. ${ }^{9}$ There is a paucity of data on the prevalence of ADHD in the Irish population; however, a school-based sample of urban 12-15 year-old children estimated that $3.7 \%$ met the criteria for ADHD. ${ }^{7}$

Boys and men are more commonly affected than girls and women; epidemiological studies report male:female ratios of 3-4:1. ${ }^{1} 411$ ADHD is also associated with comorbid psychiatric conditions such as oppositional defiant 
disorder (ODD) or conduct disorders (CD), anxiety disorders and mood disorders. ${ }^{12-14}$

Guidelines from the UK state that ADHD management requires multidisciplinary involvement that includes psychological, behavioural and educational interventions as well as pharmacological treatment. ${ }^{1315}$ Pharmacotherapy should only be initiated by an appropriately qualified physician with expertise in ADHD. ${ }^{15} 16$ Pharmacological management of ADHD is indicated as a first-line treatment option for children $(6+$ years $)$ and adolescents with severe ADHD, and for children (6+ years) and adolescents with moderate ADHD who have refused non-drug interventions or whose symptoms have not responded sufficiently to non-pharmacological intervention. ${ }^{15}$ Medications authorised for ADHD in Ireland include stimulants methylphenidate, dexamfetamine and lisdexamfetamine and non-stimulants atomoxetine and guanfacine. ${ }^{1315}$ Adverse effects associated with the use of medication for ADHD include growth retardation and psychiatric disorders with use of methylphenidate and hepatic abnormalities and psychiatric disorders with use of atomoxetine. ${ }^{17-19}$ Other psychotropic medication, including antipsychotics and antidepressants, may also be used in patients with ADHD to treat associated comorbidities. ${ }^{14}$ In addition, studies have reported off-label use of psychotropics to treat ADHD. ${ }^{20}$

The pharmacological management of ADHD has increased over the recent years in many countries. ${ }^{21-26}$ A recent study from the UK found that the use of medication for treating ADHD increased eightfold from 1995 to $2015 .{ }^{26}$ The rise was most pronounced in younger males; however, there was an increase in every age group including adults; this was thought to be due to both an increase in the number of patients diagnosed with ADHD and a higher percentage of patients with ADHD receiving pharmacological treatment. ${ }^{26}$ An Irish study found that the prescribing of ADHD medication increased in the paediatric population (0-15 years) from 2002 to $2011 . .^{21}$ However, there are no published data on the prescribing patterns of medications used for ADHD in young adults (16-24 years) in Ireland.

Since ADHD also affects adults it would be useful to assess the prescribing of ADHD medication used in young adults in Ireland and to update the previous study.

This study aimed to: (1) evaluate the prescribing patterns of medications authorised for ADHD in Ireland from 2005 to 2015 in children (0-11 years), adolescents (12-15 years) and young adults (16-24 years) according to gender and (2) to examine the concomitant use of psychotropic medication in these groups.

\section{METHODOLOGY}

\section{Patient and public involvement}

Patients or the public were not involved in the design of the study.

\section{Study design and setting}

This was a repeated cross-sectional study based on pharmacy claims data in the community setting in Ireland. Data were obtained from the Irish General Medical Services (GMS) scheme pharmacy claims database from the Health Service Executive Primary Care Reimbursement Services (HSE-PCRS). The GMS database contains basic demographic information (age and sex) and details on monthly dispensed medications coded using the WHO's Anatomical Therapeutic Chemical classification system for each individual within the scheme. ${ }^{27}$

\section{Participants}

Children and young adults aged 0-24 years. The GMS scheme is means tested and provides free health services to those who are unable to afford them. Due to eligibility criteria being based on level of income, the population covered by the GMS scheme tends to represent those from more socially deprived background. However, there is a larger proportion of the younger and older aged population covered by the scheme. It represented $35.4 \%$ those aged $\leq 24$ years old in 2015 . No information on diagnosis or disease condition or outcomes of medications is available. Children and young adults ( $\leq 24$ years) on the GMS pharmacy claims database between January 2005 and December 2015 were included in the study. The maximum length of any prescription is for 1 month, although shorter durations are possible, and repeat prescriptions can be dispensed for up to 3 months before a review with the primary care physician is required.

\section{Variables}

All authorised and marketed medications used to treat ADHD during the study period methylphenidate (N06BA04), dexamfetamine (N06BA02), lisdexamfetamine dimesylate (N06BA12) and atomoxetine (N06BA09) were extracted from the GMS database. Dispensing of concomitant psychotropic medications were also extracted from the database including antipsychotics (N05A), anxiolytics (N05B), hypnotics and sedatives (N05C) and antidepressants (N06A).

\section{Bias}

There were no adjustments made to account for any potential bias in the selection of participants for the study.

\section{Statistical analysis}

All available data were used, so formal sample size calculations were not included. The prescribing rates for all ADHD medications were compared across years, age groups (0-4 years, 5-11 years, 12-15 years and 16-24 years) and gender. Denominators for the calculation of rates are available from the Health Service Executive annual reports providing the total eligible population by age and gender for each year. This source is complete for all the years included in the study (available at https://www.sspcrs.ie/portal/annual-reporting/report/ annual). The prescribing trends are described in terms of annual prescription rates of ADHD medications and are 


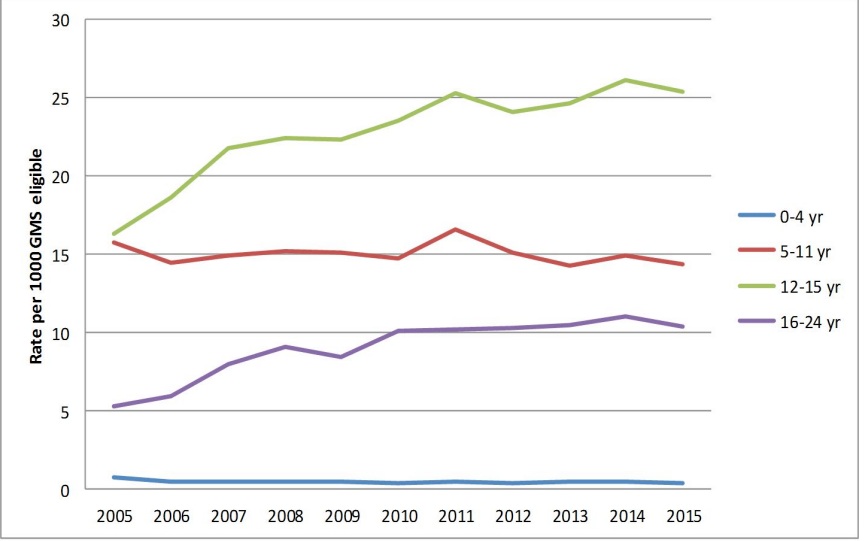

Figure 1 Rates of prescribing of attention-deficit hyperactivity disorder medications per 1000 eligible males by age groups over 2005-2015. GMS, General Medical Services.

interpreted as the prevalence of children/young adults receiving at least one medication prescription authorised for ADHD per 1000 eligible GMS population (aged 0-24 years) as of December of each year. The prescribing rates per 1000 eligible GMS population and associated 95\% CIs were calculated across years, age groups (0-4 years, 5-11 years, 12-15 years and 16-24 years) and gender. The percentage of concomitant psychotropic medication within those in receipt of ADHD medications was calculated for each year with $95 \%$ CIs. Concomitant referred to a coprescription of the medication within the same month. A linear test for trend was used to examine the percentage over time.

Negative binomial regression was used to determine trends in prevalence over time with an offset term $(\log$ (GMS population) ), and year, age group, gender were included in the model. The negative binomial regression can be used to analyse the prevalence risk ratios with $95 \% \mathrm{CIs}^{28}{ }^{28}$ Significance at $\mathrm{p}<0.05$ was assumed. Data analysis was performed using Stata V.11 (StataCorp, College Station, Texas, USA) and SAS V.9.3 (SAS Institute).

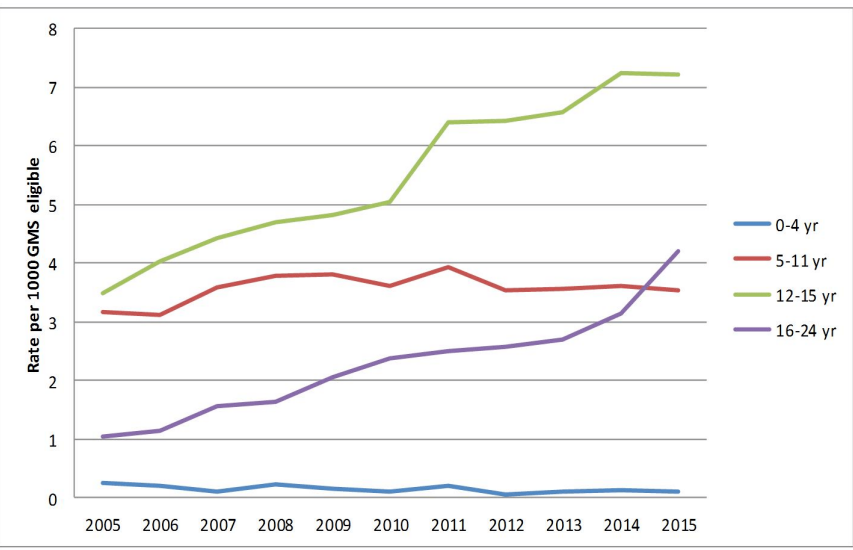

Figure 2 Rates of prescribing of attention-deficit hyperactivity disorder medications per 1000 eligible females by age groups over 2005-2015. GMS, General Medical Services.

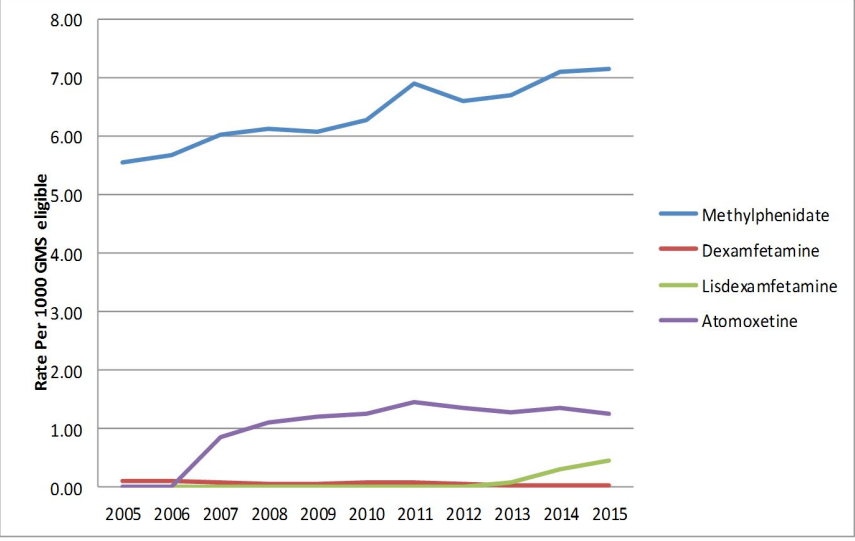

Figure 3 Rates of attention-deficit hyperactivity disorder drugs per 1000 eligible population (0-24 years) by type of drug dispensed. GMS, General Medical Services.

\section{RESULTS}

\section{Population sample}

During the study period, the number of children and young adults (0-24 years) on ADHD drugs as identified from the HSE-PCRS database ranged from 1913 in 2005 to 4853 in 2015 , of whom $82.7 \%$ and $78.3 \%$ were male (2005 and 2015, respectively).

\section{Prescribing trends}

The rate of any ADHD medication per 1000 eligible GMS population aged $<25$ years increased significantly over time from 5.61 (95\% CI 5.36 to 5.86) in 2005 to 8.36 (95\% CI 8.13 to 8.60$)$ in $2015(\mathrm{p}<0.0001)$.

Figures 1 and 2 show the prescription rates of any medication authorised for ADHD per 1000 eligible male and female populations over time. The rates overall were three to five times higher in males compared withfemales.

Negative binomial regression showed significant increases over time (per year) for ADHD prescribing rate in boys/men in the oldest age categories; that is, for 12-15 year age group $(\mathrm{RR}=1.04,95 \%$ CI 1.03 to $1.05, \mathrm{p}<0.0001)$ and 16-24 year age groups ( $R R=1.06,95 \%$ CI 1.04 to 1.09 , $\mathrm{p}<0.0001)$. For girls/women, significant increases over time were also found, similar to boys/men in the oldest age categories; for $12-15$ year age group $(\mathrm{RR}=1.07,95 \%$ CI 1.06 to $1.09, \mathrm{p}<0.0001)$ and $16-24$ year age groups $(\mathrm{RR}=1.13,95 \%$ CI 1.11 to $1.15, \mathrm{p}<0.0001)$.

Figure 3 provides the trends in rates of ADHD prescriptions over time; the highest rate was for methylphenidate, which significantly increased over time ( $R R=1.03,95 \%$ CI 1.02 to $1.04, \mathrm{p}<0.0001)$, with atomoxetine the next highest with fairly stable use over time .

Table 1 provides the numbers and percentages $(95 \%$ CIs) in receipt of ADHD medications with coprescribed concomitant psychotropic medication. The percentage of patients on concomitant antidepressants increased significantly from approximately $2 \%$ in 2005 to $6 \%$ in $2015(\mathrm{p}<0.0001)$. The percentage of patients on antipsychotics slightly increased from 6\% in 2005 to $8 \%$ in 2015 but not significantly $(\mathrm{p}=0.30)$. During the study period 
Table 1 Number, percentage and $95 \% \mathrm{Cl}$ of concomitant prescribing in those on ADHD drugs over time (all ages $\leq 24$ years combined)

\begin{tabular}{|c|c|c|c|c|c|c|c|c|c|}
\hline \multirow[b]{2}{*}{ Year } & \multicolumn{4}{|c|}{ Number } & \multicolumn{5}{|c|}{ Percentage (95\% Cl) } \\
\hline & Antipsychotics & Anxiolytics & Hypnosedatives & Antidepressants & $\begin{array}{l}\text { Total on } \\
\text { ADHD } \\
\text { drugs }\end{array}$ & Antipsychotics & Anxiolytics & Hypnosedatives & Antidepressants \\
\hline 2005 & 112 & 38 & 11 & 35 & 1913 & $\begin{array}{l}5.85 \% \\
(4.80 \% \text { to } \\
6.91 \%)\end{array}$ & $\begin{array}{l}1.99 \% \\
(1.36 \% \text { to } \\
2.61 \%)\end{array}$ & $\begin{array}{l}0.58 \% \\
(0.24 \% \text { to } 0.91 \%)\end{array}$ & $\begin{array}{l}1.83 \% \\
(1.23 \% \text { to } 2.43 \%)\end{array}$ \\
\hline 2006 & 145 & 41 & 12 & 41 & 2101 & $\begin{array}{l}6.90 \% \\
(5.82 \% \text { to } \\
7.99 \%)\end{array}$ & $\begin{array}{l}1.95 \% \\
(1.36 \% \text { to } \\
2.54 \%)\end{array}$ & $\begin{array}{l}0.57 \% \\
(0.25 \% \text { to } 0.89 \%)\end{array}$ & $\begin{array}{l}1.95 \% \\
(1.36 \% \text { to } 2.54 \%)\end{array}$ \\
\hline 2007 & 197 & 51 & 12 & 44 & 2516 & $\begin{array}{l}7.83 \% \\
(6.78 \% \text { to } \\
8.88 \%)\end{array}$ & $\begin{array}{l}2.03 \% \\
(1.48 \% \text { to } \\
2.58 \%)\end{array}$ & $\begin{array}{l}0.48 \% \\
(0.21 \% \text { to } 0.75 \%)\end{array}$ & $\begin{array}{l}1.75 \% \\
(1.24 \% \text { to } 2.26 \%)\end{array}$ \\
\hline 2008 & 205 & 50 & 24 & 63 & 2830 & $\begin{array}{l}7.24 \% \\
(6.29 \% \text { to } \\
8.20 \%)\end{array}$ & $\begin{array}{l}1.77 \% \\
(1.28 \% \text { to } \\
2.25 \%)\end{array}$ & $\begin{array}{l}0.85 \% \\
(0.51 \% \text { to } 1.19 \%)\end{array}$ & $\begin{array}{l}2.23 \% \\
(1.68 \% \text { to } 2.77 \%)\end{array}$ \\
\hline 2009 & 245 & 59 & 30 & 87 & 3235 & $\begin{array}{l}7.57 \% \\
(6.66 \% \text { to } \\
8.49 \%)\end{array}$ & $\begin{array}{l}1.82 \% \\
(1.36 \% \text { to } \\
2.28 \%)\end{array}$ & $\begin{array}{l}0.93 \% \\
(0.60 \% \text { to } 1.26 \%)\end{array}$ & $\begin{array}{l}2.69 \% \\
(2.13 \% \text { to } 3.25 \%)\end{array}$ \\
\hline 2010 & 294 & 56 & 49 & 111 & 3741 & $\begin{array}{l}7.86 \% \\
(7.00 \% \text { to } \\
8.72 \%)\end{array}$ & $\begin{array}{l}1.50 \% \\
(1.11 \% \\
\text { to } 1.89 \%)\end{array}$ & $\begin{array}{l}1.31 \% \\
(0.95 \% \text { to } 1.67 \%)\end{array}$ & $\begin{array}{l}2.97 \% \\
(2.42 \% \text { to3.51\%) }\end{array}$ \\
\hline 2011 & 340 & 71 & 52 & 149 & 4349 & $\begin{array}{l}7.82 \% \\
(7.02 \% \text { to } \\
8.62 \%)\end{array}$ & $\begin{array}{l}1.63 \% \\
(1.26 \% \text { to } \\
2.01 \%)\end{array}$ & $\begin{array}{l}1.20 \% \\
(0.87 \% \text { to } 1.52 \%)\end{array}$ & $\begin{array}{l}3.43 \% \\
(2.89 \% \text { to } 3.97 \%)\end{array}$ \\
\hline 2012 & 335 & 71 & 56 & 176 & 4633 & $\begin{array}{l}7.23 \% \\
(6.48 \% \text { to } \\
7.98 \%)\end{array}$ & $\begin{array}{l}1.53 \% \\
(1.18 \% \text { to } \\
1.89 \%)\end{array}$ & $\begin{array}{l}1.21 \% \\
(0.89 \% \text { to } 1.52 \%)\end{array}$ & $\begin{array}{l}3.80 \% \\
(3.25 \% \text { to } 4.35 \%)\end{array}$ \\
\hline 2013 & 346 & 75 & 70 & 236 & 4738 & $\begin{array}{l}7.30 \% \\
(6.56 \% \text { to } \\
8.04 \%)\end{array}$ & $\begin{array}{l}1.58 \% \\
(1.23 \% \text { to } \\
1.94 \%)\end{array}$ & $\begin{array}{l}1.48 \% \\
(1.13 \% \text { to } 1.82 \%)\end{array}$ & $\begin{array}{l}4.98 \% \\
(4.36 \% \text { to } 5.60 \%)\end{array}$ \\
\hline 2014 & 392 & 98 & 90 & 262 & 4875 & $\begin{array}{l}8.04 \% \\
(7.28 \% \text { to } \\
8.80 \%)\end{array}$ & $\begin{array}{l}2.01 \% \\
(1.62 \% \text { to } \\
2.40 \%)\end{array}$ & $\begin{array}{l}1.85 \% \\
(1.47 \% \text { to } 2.22 \%)\end{array}$ & $\begin{array}{l}5.37 \% \\
(4.74 \% \text { to } 6.01 \%)\end{array}$ \\
\hline 2015 & 399 & 84 & 100 & 298 & 4853 & $\begin{array}{l}8.22 \% \\
(7.45 \% \text { to } \\
8.99 \%)\end{array}$ & $\begin{array}{l}1.73 \% \\
(1.36 \% \text { to } \\
2.10 \%)\end{array}$ & $\begin{array}{l}2.06 \% \\
(1.66 \% \text { to } 2.46 \%)\end{array}$ & $\begin{array}{l}6.14 \% \\
(5.47 \% \text { to } 6.82 \%)\end{array}$ \\
\hline
\end{tabular}

ADHD, attention-deficit hyperactivity disorder.

2005-2015, the concomitant use of hypnosedatives and anxiolytics ranged from $1 \%$ to $2 \%$ with a significant increase in hypnotics from $0.6 \%$ to $2.1 \%$ from 2005 to $2015(\mathrm{p}<0.0001)$ and significant decrease in anxiolytics from $2.0 \%$ to $1.7 \%$ ( $\mathrm{p}=0.002)$. Further information on the concomitant use of medicines by age $(<16$ years and 16-24 years) is available in online supplementary appendix 1 .

\section{DISCUSSION}

This study found that the prescribing rates for ADHD medications increased significantly from 2005 to 2015 for both boys/men and girls/women based on data from the HSE-PCRS database. The results update the findings from a previous Irish study undertaken in children, which showed a similar increase in the prescribing of psychostimulants from 2002 to 2011 and in addition provide data on adolescent usage. ${ }^{21}$ The results also showed an increased use of concomitant antidepressants, antipsychotics and hypnotics over time. These findings are in keeping with results from other epidemiological studies which showed an increase in prescribing of medication for ADHD over time; a UK study reported an eightfold increase in prescribing rates over 20 years, ${ }^{26}$ while increasing prescribing rates have also been reported in other countries including the USA, Israel, Spain, the Netherlands and Denmark, ${ }^{22-25} 29$ during a similar time period.

The prescribing rate was three to five times higher in boys/men than girls/women, which was expected based on previous studies and on epidemiological studies. ${ }^{1411262930}$ These findings may also reflect underdiagnosis of the condition in girls, ${ }^{31}$ since the disparity in treatment between males and females appears to narrow somewhat with increasing age. It has been suggested that the higher treatment rates in boys may relate to the disruptive behaviour exhibited at school and social situations, resulting in higher referral rates for boys. ${ }^{24}$ The highest prescribing rate for males in this study occurred in the 12-15-year-old age group, followed by the 5-11 and 16-24-year-old age groups, respectively; similar patterns were reported for the female age groups. These results 
replicate findings in other studies and increase the generalisability of the study findings. ${ }^{26}{ }^{29}$ The increase in prescribing rates in the 16-24-year-old age group is of particular interest as ADHD was previously considered to resolve during adolescence and young adulthood. ${ }^{1}$ However, it is now recognised that up to two-thirds of those with childhood ADHD have symptomatic features continuing into adulthood. ${ }^{3}$ The increased prescribing rate in the 16-24-year-old age group may be reflective of this, and it has been reported in other studies. ${ }^{26}$ It is of note that during the time period of this study, there was concern regarding the lack of adult ADHD services in Ireland, and it was recognised that there was an urgent need to develop adult ADHD services. ${ }^{32}$ An adult ADHD National Clinical Programme (NCP) has now been introduced in Ireland. ${ }^{33}$

In this study, methylphenidate was the most frequently prescribed ADHD medication, accounting for more than 98\% of all ADHD medications in 2005 and $80 \%$ in 2015 , followed by atomoxetine. Methylphenidate has been used for the last 50 years, while the other stimulants dexamphetamine and lisdexamphetamine have only been authorised in Ireland since 2014 and 2013, respectively, reflected in the very low prescribing rates noted in the study. The prescribing of the non-stimulant atomoxetine, which was first authorised in 2006, appears to have plateaued in recent years. Methylphenidate was also the most frequently prescribed ADHD medication in studies from other European countries. ${ }^{24} 2630$ The stimulants are recommended as first-line pharmacological treatment, while the non-stimulants are only recommended if there are contraindications to use of the stimulants. ${ }^{11} 15$ The USA has a higher prescribing rate of medications for ADHD compared with many European countries which may be due to the difference in application of diagnostic criteria for ADHD. ${ }^{1}$ In addition, in many European countries guidelines recommend that pharmacological management should only be initiated by an appropriately qualified physician with expertise in ADHD. ${ }^{15} 2930$ However, it has also been suggested that ADHD may be under-recognised in some European countries. ${ }^{26} 29$ The increase in prescribing of ADHD medicines seen in this and other recent studies may be due to increased diagnosis and treatment of a previously unrecognised disease. In Ireland, the majority of children and adolescents with suspected ADHD are referred to Child and Adolescent Mental Health Services (CAMHS) for assessment, while some children are assessed by paediatricians. ${ }^{34}$ During the study period, there was an increase in the number of CAMHS available in Ireland from 49 in 2008 to 63 in 2015 , which may have contributed to an increase in the prescribing of ADHD medications during the study due to increased diagnosis of the condition. ${ }^{35}$

The increase in prescribing of ADHD medications reported in many countries has led to some concern that this may represent inappropriate prescribing of these medications. ${ }^{232536}$ At the time of the study, pharmacotherapy was not recommended for preschool children and was recommended as first-line treatment only for severe ADHD in all school-aged children and young people. In addition, pharmacological management should always form part of a multidisciplinary treatment plan, with regular monitoring while on treatment. ${ }^{15}$ Although this study showed a statistically significant rise in the rate of prescribing of ADHD medications during the study period, the rates recorded at the end of the study period (2015) are still considerably less than those reported within a similar UK population for the same time period. ${ }^{26}$ However, it is not possible to comment definitively on the appropriateness of the ADHD medication being prescribed as clinical information is not available due to the design of the study.

This study also investigated the coprescribing of psychotropic medicines in the study group, and it found a significant increase in the prescribing of concomitant psychotropic medicines from 2005 to 2015. In particular, there was a significant increase in the concomitant prescribing of antidepressants from $2 \%$ to $6 \%$ and a non-significant increase in antipsychotics from $6 \%$ to $8 \%$. These trends in concomitant medicines were mostly evident in the adolescents/young adult with an increase from $4.7 \%$ to $15.1 \%$ in concomitant use of antidepressants and from $5.8 \%$ to $13.7 \%$ for antipsychotics from 2005 to 2015; there was little or no change in concomitant medicines in those aged $<16$ years over time. This latter results consistent with a previous Irish study which showed no increase in similar coprescribing over time in children. ${ }^{21}$ That study, which looked at coadministration of psycholeptics, antipsychotics, anxiolytics, hypnotics and sedatives and antidepressants with psychostimulants from 2002 to 2011, found that on average 10\% of their study participants received concomitant psychotropic medication; however, the proportion did not change significantly over the study period. ${ }^{21}$ A study of six European countries from 2013 found that $14 \%$ of children and adolescents receiving medication for ADHD were treated concomitantly with psychotropic medication, ranging from $4.1 \%$ in Germany to $33 \%$ in Italy. ${ }^{20}$ In that study, atypical antipsychotics were the most commonly used psychotropic medication followed by anxiolytics. A study from the USA in 2009 found the prevalence of concomitant use of psychotropic use in children ranging from $12.6 \%$ for non-comorbid ADHD to $42 \%$ for comorbid ADHD ${ }^{37}$ It is known that ADHD is associated with psychiatric comorbidities such as depression, ODD and CD, ${ }^{38} 39$ which may explain the concomitant psychotropic medication. However, it may also be due to off-label prescribing for children with severe ADHD who are not responding to first-line ADHD monotherapy.

This study has a number of strengths including the large study size and accurate ascertain of medicines. However, there are some limitations including the lack of any clinical information on participants, inclusion of a more socially deprived population and the fact that data refer to medicines dispensed rather than taken. As discussed previously, the lack of clinical information on participants 
precludes comment on the appropriateness of the medication being used in the study. The inclusion of a more socially deprived population may limit the generalisability of the study findings, as there is some evidence of an association between socioeconomic disadvantage and risk of ADHD. ${ }^{40}$ In addition, there may be bias introduced as a result of the potential off-label use of ADHD medicines in the treatment of other conditions such as autistic spectrum disorder and other psychiatric disorders. ${ }^{29}$ Therefore, the findings of this study may be an overestimate of the use of these drugs for ADHD. In addition, some patients with severe ADHD not responding to drugs authorised for ADHD may be treated with off-label use of other drugs such as bupropion, clonidine and antipsychotics ${ }^{20}$ which will not be captured in this study.

\section{CONCLUSIONS}

Our study found an increase in the overall prescribing rates of ADHD medications from 2005 to 2015, principally due to increased prescribing of methylphenidate. This may reflect increasing awareness and diagnosis of the condition, possibly due to increased facilities for managing neuropsychiatric illness in children and adolescents over time. The study also found an increase in the concomitant prescribing of antipsychotics and antidepressants, which may reflect increasing levels of comorbidity in ADHD and increased access to child and adolescent mental health services over time. The findings of the study support the introduction of the NCP for adult ADHD services and the need for additional resources to CAMHS, where the majority of children with ADHD are assessed. It would be beneficial in future research studies if linkage between prescribing data and clinical data, such as diagnosis and outcomes data, were possible. This would enable research questions on the appropriateness of ADHD and concomitant medicines and the likely impact these have on shortterm, medium-term and long-term outcomes.

\section{Twitter Kathleen E Bennett @pharmacoepircsi}

Acknowledgements We would like to thank the HSE-PCRS for providing the data on which the study was based.

Contributors All authors (MMA, KEB and MT) are responsible for the substantial contributions to the conception or design of the work or the acquisition, analysis or interpretation of data for the work; drafting the work or revising it critically for important intellectual content; final approval of the version to be published and agreement to be accountable for all aspects of the work in ensuring that questions related to the accuracy or integrity of any part of the work are appropriately investigated and resolved.

Funding Kathleen Bennett was funded by the Health Research Board in Ireland (HRB RL-15-1579).

\section{Competing interests None declared.}

Patient and public involvement Patients and/or the public were not involved in the design, conduct, reporting or dissemination plans of this research.

Patient consent for publication Not required.

Ethics approval Ethical approval for this study was not required as permission was given by the data controller (HSE-PCRS) to use the GMS pharmacy claims data which were anonymised.

Provenance and peer review Not commissioned; externally peer reviewed.
Data availability statement Data may be obtained from a third party and are not publicly available. Data were made available from the Health Service Executive PCRS only for the purpose of this study.

Open access This is an open access article distributed in accordance with the Creative Commons Attribution Non Commercial (CC BY-NC 4.0) license, which permits others to distribute, remix, adapt, build upon this work non-commercially, and license their derivative works on different terms, provided the original work is properly cited, appropriate credit is given, any changes made indicated, and the use is non-commercial. See: http://creativecommons.org/licenses/by-nc/4.0/.

ORCID iD

Kathleen E Bennett http://orcid.org/0000-0002-2861-7665

\section{REFERENCES}

1 Thapar A, Cooper M. Attention deficit hyperactivity disorder. The Lancet 2016;387:1240-50.

2 Bolea-Alamañac B, Nutt DJ, Adamou M, et al. Evidence-Based guidelines for the pharmacological management of attention deficit hyperactivity disorder: update on recommendations from the British association for psychopharmacology. J Psychopharmacol 2014;28:179-203.

3 Faraone SV, Biederman J, Mick E. The age-dependent decline of attention deficit hyperactivity disorder: a meta-analysis of follow-up studies. Psychol Med 2006;36:159-65.

4 European Medicines Agency. Guideline on the clinical investigation of medicinal products for the treatment of attention deficit hyperactivity disorder (ADHD), 2016. Available: www.ema.europa.eu

5 Fayyad J, De Graaf R, Kessler R, et al. Cross-National prevalence and correlates of adult attention-deficit hyperactivity disorder. $\mathrm{Br} \mathrm{J}$ Psychiatry 2007;190:402-9.

6 Polanczyk GV, Salum GA, Sugaya LS, et al. Annual research review: a meta-analysis of the worldwide prevalence of mental disorders in children and adolescents. J Child Psychol Psychiatry 2015;56:345-65.

7 Lynch F, Mills C, Daly I, et al. Challenging times: prevalence of psychiatric disorders and suicidal behaviours in Irish adolescents. $J$ Adolesc 2006;29:555-73.

8 Skounti M, Philalithis A, Galanakis E. Variations in prevalence of attention deficit hyperactivity disorder worldwide. Eur J Pediatr 2007;166:117-23.

9 Willcutt EG. The prevalence of DSM-IV attention-deficit/hyperactivity disorder: a meta-analytic review. Neurotherapeutics 2012;9:490-9.

10 Kavanagh G, O'Hanrahan S, Hughes G, et al. Review of clinical guidelines for children and adolescents with attention deficit hyperactivity disorder and their application to an Irish context. Ir J Psychol Med 2015;32:283-93.

11 Zalsman G, Shilton T. Adult ADHD: a new disease? Int J Psychiatry Clin Pract 2016;20:70-6.

12 Garnock-Jones KP, Keating GM. Spotlight on atomoxetine in attention-deficit hyperactivity disorder in children and adolescents. CNS Drugs 2010;24:85-8.

13 SIGN. SIGN guidelines 112: management of attention deficit and hyperkinetic disorders in children and young people, 2016. Available: www.sign.ac.uk

14 Bali V, Kamble PS, Aparasu RR. Predictors of concomitant use of antipsychotics and stimulants and its impact on stimulant persistence in pediatric attention deficit hyperactivity disorder. $J$ Manag Care Spec Pharm 2015;21:486-98.

15 NICE. NICE clinical guideline: attention deficit hyperactivity disorder: diagnosis and management, published 24 September 2008 (last updated February 2016), 2016. Available: www.nice.org.uk/guidance/ $\operatorname{cg} 72$

16 Kapur S, Paton C, Taylor DM. The Maudsley prescribing guidelines in psychiatry, 2015.

17 Electronic Medicines Compendium. Smpc Ritalin $®$ immediate release (methylphenidate), 2016. Available: www.medicines.ie

18 Health Products Regulatory Authority. SmPC Tentin $®$ (dexamfetamine), 2016. Available: www.hpra.ie

19 Electronic Medicines Compendium. SmPC Strattera ${ }^{\circledR}$ (atomoxetine), 2016. Available: www.medicines.ie

20 Sikirica V, Fridman M, Bruno A, et al. Concomitant pharmacotherapy of psychotropic medications in Eu children and adolescents with attention-deficit/hyperactivity disorder. Drugs R D 2013;13:271-80.

21 Boland F, Galvin R, Reulbach U, et al. Psychostimulant prescribing trends in a paediatric population in Ireland: a national cohort study. BMC Pediatr 2015;15:18. 
22 Chai G, Governale L, McMahon AW, et al. Trends of outpatient prescription drug utilization in US children, 2002-2010. Pediatrics 2012;130:23-31.

23 Ponizovsky AM, Marom E, Fitoussi I. Trends in attention deficit hyperactivity disorder drugs consumption, Israel, 2005-2012. Pharmacoepidemiol Drug Saf 2014;23:534-8.

24 Hodgkins P, Sasané R, Meijer WM. Pharmacologic treatment of attention-deficit/hyperactivity disorder in children: incidence, prevalence, and treatment patterns in the Netherlands. Clin Ther 2011;33:188-203.

25 Treceño C, Martín Arias LH, Sáinz M, et al. Trends in the consumption of attention deficit hyperactivity disorder medications in Castilla Y León (Spain): changes in the consumption pattern following the introduction of extended release methylphenidate. Pharmacoepidemiol Drug Saf 2012;21:435-41.

26 Renoux C, Shin J-Y, Dell'Aniello S, et al. Prescribing trends of attention-deficit hyperactivity disorder (ADHD) medications in UK primary care, 1995-2015. Br J Clin Pharmacol 2016;82:858-68.

27 WHO. Collaborating centre for drug statistics methodology: anatomical therapeutic chemical (ATC) classification index. who collaborating centre for drug statistics methodology. Norway: Oslo, 2017. https://www.whocc.no/

28 Agresti A. Categorical data analysis. New York, NY: John Wiley and Sons, 2002.

29 Dalsgaard S, Nielsen HS, Simonsen M. Five-Fold increase in national prevalence rates of attention-deficit/hyperactivity disorder medications for children and adolescents with autism spectrum disorder, attention-deficit/hyperactivity disorder, and other psychiatric disorders: a Danish register-based study. J Child Adolesc Psychopharmacol 2013;23:432-9.

30 Pottegård A, Bjerregaard BK, Glintborg D, et al. The use of medication against attention deficit hyperactivity disorder in
Denmark: a drug use study from a national perspective. Eur $\mathrm{J}$ Clin Pharmacol 2012;68:1443-50.

31 Castle L, Aubert RE, Verbrugge RR, et al. Trends in medication treatment for ADHD. J Atten Disord 2007:10:335-42.

32 McNicholas F, Adamson M, McNamara N, et al. Who is in the transition gap? transition from CAMHS to AMHS in the Republic of Ireland. Ir J Psychol Med 2015;32:61-9.

33 Health Services Executive. Health service executive Irish national clinical programme for ADHD in adults, 2020. Available: https://www. hse.ie/eng/about/who/cspd/ncps/mental-health/adhd/

34 Honorio Neto F, Tatlow-Golden M, Mulligan A, et al. Attitudes and reported practice of paediatricians and child psychiatrists regarding the assessment and treatment of ADHD in Ireland. Ir J Psychol Med 2018;35:181-91.

35 HSE Mental Health Division. Delivering specialist mental health services 2014-2015, 2017. Available: www.hse.ie

36 Pauly V, Frauger E, Lepelley M, et al. Patterns and profiles of methylphenidate use both in children and adults. Br J Clin Pharmacol 2018;84:1215-27.

37 Betts KA, Sikirica V, Hodgkins P, et al. Period prevalence of concomitant psychotropic medication usage among children and adolescents with attention-deficit/hyperactivity disorder during 2009. $J$ Child Adolesc Psychopharmacol 2014;24:260-8.

38 Chan E, Fogler JM, Hammerness PG. Treatment of attention-deficit/ hyperactivity disorder in adolescents: a systematic review. JAMA 2016;315:1997-2008.

39 Pliszka SR. Psychiatric comorbidities in children with attention deficit hyperactivity disorder: implications for management. Paediatr Drugs 2003;5:741-50.

40 Russell AE, Ford T, Williams R, et al. The association between socioeconomic disadvantage and attention deficit/hyperactivity disorder (ADHD): a systematic review. Child Psychiatry Hum Dev 2016;47:440-58. 